This PDF is a selection from a published volume from the National Bureau of Economic Research

Volume Title: The Rate and Direction of Inventive Activity Revisited

Volume Author/Editor: Josh Lerner and Scott Stern, editors

Volume Publisher: University of Chicago Press

Volume ISBN: 0-226-47303-1; 978-0-226-47303-1 (cloth)

Volume URL: http://www.nber.org/books/lern11-1

Conference Date: September 30 - October 2, 2010

Publication Date: March 2012

Chapter Title: Why Is It So Difficult to Translate Innovation

Economics into Useful and Applicable Policy Prescriptions?

Chapter Authors: Dominique Foray

Chapter URL: http://www.nber.org/chapters/c12378

Chapter pages in book: (p. 673 - 678) 


\title{
Why Is It So Difficult to Translate Innovation Economics into Useful and Applicable Policy Prescriptions?
}

\author{
Dominique Foray
}

Bronwyn Hall already mentioned the "Knowledge for Growth" Expert Group at the European Commission in which I participated for four years as cochairman, together with Bronwyn, Paul, and people like Philippe Aghion, Jacques Mairesse, Ramon Marimon, Reinhilde Veugelers, André Sapir, Stan Metcalfe, and a few others. As part of our activities, every two or three months we held discussions with the Research Commissioner Janesz Potocnik. As he was very committed to our group, we were all quite motivated, not to give any policy prescriptions but to discuss interesting innovation policy issues. And so I will take this experience as a basis for what I want to say: how difficult it is to translate the findings of innovation economics into well-understood and potentially exploitable policy prescriptions. And in doing so I will address three categories of difficulties.

I would like to start with this quotation from George Stigler in his paper, "Economists and Public Policy" in 1982 to discuss a first difficulty: "Once the practice of testing our predictions by examining the evidence became general practice, economists' advice - that is, the advice that survived the empirical tests - would be heeded by the society" (13). Of course, Stigler argued, this is a myth based on a misperception of how our results can attract the attention of policymakers and society as a whole, and can only be applied to innovation policy research. Once innovation policy research and innovation economics reach the point of becoming a strong empirically disciplined science, it becomes much more difficult to ensure that its results and findings are understood and properly used by policymakers. In fact, the vast majority of

Dominique Foray holds the chair in Economics and Management of Innovation at École Polytechnique Fédérale de Lausanne (EPFL). 
policymakers still proceed on the basis of only casual understanding, uninformed by systematic empirical inquiries into the process of innovation.

I would like to take an example of this problem and then discuss why it might be amplified in our discipline. An illustration of Stigler's argument concerns the progress achieved by innovation policy research in the domain of the evaluation of government support for commercial R\&D.

Some economists have made the point that some of these programs are not expanding the amount of R\&D but simply transferring the cost of commercial $\mathrm{R} \& \mathrm{D}$ to the government. This is a great, but difficult to understand, empirical result: a funded project that is successful says nothing about whether the project needed a subsidy. But this is something that is very hard to take for a policymaker, who is used to interpreting the success of a funded project as evidence that the public program is great and useful in stimulating innovation. And so it might be very difficult for a policymaker and also for a government to take the opposite view, which in a sense is the view consistent with this empirical finding, that a high rate of failures of projects subsidized by a program is an indication that the public program targeted high-risk projects with little chance of being successful.

And so I think that it is quite clear that the more our prescriptions are based on the fine empirical analysis of what is going on - with quite complex results - the less likely they will be heeded by policymakers and government. And perhaps the difficulty highlighted by Stigler and illustrated by the case just described is even greater in our field because we have competitors in this business of translating findings into policy prescriptions; competitors who are delivering far more simple messages that policymakers care to listen to. Here an interesting episode in the history of the "Knowledge for growth" Expert Group comes to my mind. This concerns a Booz Allen Hamilton report on R\&D spenders, to which we wrote a response with Bronwyn Hall and Jacques Mairesse. This report had much greater impact in the European press, by the way. It is an empirical study relating to a large population of top R\&D spenders about the relationships between R\&D and firms' performance and it concludes that the share of spending devoted to $R \& D$ has no relationship to the economic performance of firms. Firms that spend less on $\mathrm{R} \& \mathrm{D}$ than competitors have superior performances, or these companies that spend less than their competitors on $\mathrm{R} \& \mathrm{D}$, yet outpace their industries across a wide range of performance metrics. And so the idea that $R \& D$ is just an input and does not tell us anything about innovation is floating in the air, and policymakers like the simple message: Do not invest so much in $\mathrm{R} \& \mathrm{D}$ and you will perform better.

There are a great many methodological problems in the empirical study, as well as misinterpretations of their own results. Our chairperson could explain that better than I. However, it had a big impact on policymaking discussion, in spite of the bulk of evidence accumulated by empirical research since the conference whose anniversary we are celebrating in this volume. 
And I think one reason is that the message on this topic, coming from the economics of innovation, is much more complex. Our message is that (a) the uncertainty inherent in the processes of research and innovation implies an equivalent uncertainty in the profitability of these investments at the level of an individual firm; and (b) there is no doubt that such profitability when measured at the aggregate level or for society as a whole has been shown to be as high as, or higher than, the profitability of investment in the physical capital. In short, do not confuse what is true for the forest as a whole with what is true for each individual tree! This is a more complex message for a policymaker and is made even more complex by all the footnotes he or she can read about the difficulties of measuring R\&D output at firm level and interpreting the results - in particular difficulties related to the measurement of prices in the case of new products, or to the question of the lag between investment in R\&D and its contribution to performance; all footnotes involving plenty of nuances that do not appear in the Booz Allen Hamilton report.

And I would like to close this story with its final anecdotal "fireball," which illustrates part of the problem of the difficulties of competing for policy attention with companies like Booz Allen Hamilton. We responded to this report with a paper written with Jacques and Bronwyn, ${ }^{1}$ and started discussions with Harvard Business Review to publish it because, indeed, there are sometimes papers in this journal that are intended to explain methodological issues of empirical research in economics and management to managers. So we started talking with the editorial board, which was nice, but at some point, there was a long silence from the journal. And then we learned that - let's call him Mr. X — who was the editor we had dealt with, had left the journal. And where do you think he went? To Booz Allen Hamilton as a senior consultant!

And so we abandoned our efforts to find a journal to publish our response. So that is the first difficulty involved in translating our findings into policy prescription, largely based on Stigler's myth.

The second point is really simple. It concerns the inherent limitation of what we can generate as policy prescription from some interesting and useful findings. Let's take as an example the case of coordination failure. I think this is an important concept. Listening to Tim Bresnahan, it is obvious that coordination between different classes of agents is needed, although it is not easy, to ensure the full deployment of a GPT involving plenty of coinvention of application processes.

Now understanding the basic principles of coordination problems obviously does not take one very far in the direction of useful, practical conclusions as to how to construct a technology policy. ${ }^{2}$ And so the practical 
implementation of a policy to deal with coordination involves answering a set of questions that is not simple. What activities in what firms need to be coordinated, and in what way? An appropriate choice of policy tools requires a detailed understanding of the externalities and innovation complementarities. And so the information requirements, at a practical level, raise serious questions about the possibilities for government policies to correct coordination problems in the real world. And so in many cases, the practicality and costs of policy intervention make some failures that we have identified too expensive or too difficult to correct. We made this point with Philippe Aghion and Paul David in a paper published recently in Research Policy. ${ }^{3}$

My last point about our difficulties in translating research findings into policy prescription is in a sense more our fault. This concerns our biased research agenda. For at least thirty years and particularly in Europe, it seems to me that the policy research agenda in academia focused almost exclusively on the design, development, and evaluation of tools, instruments, and programs aimed at increasing the rate of innovation in the system.

But beyond the infinite sophistication regarding the questions of the design, effectiveness, and impacts of these tools and instruments aimed at increasing the rate of innovation (such as fiscal measures, direct subsidies, and the improvement of framework conditions), the other area, which relates to the direction of inventive activities, has been relatively unexplored in policy research discussion. ${ }^{4}$ At this conference, it is quite tempting to recall that the seminal book of our profession, which we are celebrating today, was entitled The Rate and the Direction of Inventive Activities!

Why such a bias in the agenda? The arguments are as follows: yes, there are market failures, particularly in the area of $R \& D$ in the form of positive externalities (knowledge spillovers), which drive a wedge between private and social returns from R\&D investment. Because of these positive externalities, some socially useful investments will not appear as being privately profitable, so the market will not sufficiently support the activities and policy needed to correct this failure. But the next argument is that government failures are expected to be greater than market failures (although there is little evidence as to how much greater they are). And so the main message relates to neutrality; the resources allocated through the policy mechanism must respond to market signals rather than bureaucratic directives. An efficient policy does not select projects according to preferred fields but responds to demand that arises spontaneously from the industry. Departing from neutrality in order to influence the direction of innovation-providing subsidies to favored firms or sectors-is prone to misallocate sources since it implies guessing future technological and market developments. This opens the door to all

3. See Aghion, David, and Foray (2009).

4. See Foray (2009). 
those little monsters that economists always try to eradicate, which they call wrong choices, picking winners, and market distortions.

In short, the message was: "Do not undertake actions to influence the direction of innovation but let market prices reflect the future scarcity of commodities so that certain kinds of innovation will be induced by changes in relative prices." There is obviously evidence of inducement - for instance, some kind of correlation between energy prices and energy-related innovations can be found - but in many cases the price system does not do the job (does not reflect future scarcity) and therefore has little effect on the direction of innovation. And when there are inducement effects, the timescale seems to be decades. So for policies that deal with prices, taxes, and standards to have maximum impacts, long periods of time are required.

Thus in the area of policy research and discussion the last three decades have been dominated by the argument that market failures need to be corrected in order to reach the desirable level of investments, but where these investments should go should not be a concern for policies. It is much better to leave this issue to the magical chaos of the "blind watchmaker." Any notion of specialization policy or top-down strategic initiatives has become a taboo in policy discussion, particularly in the large international policy forums as well as in the European Commission.

But this economist's discourse is radically out of step with reality. While economists claim to be the most assiduous partisans of neutral R\&D and innovation policies, which therefore do not distort the logics of marketdriven resource allocation, the share of resources allocated to missions and large programs has always accounted for a large share of central government R\&D spending within the Organization for Economic Cooperation and Development (OECD). Thus, as D. Mowery has shown, 90 percent of federal R\&D expenditure in the United States is not allocated based on a principle of market failure but has rather been oriented by a "mission" logic.

The result of this discrepancy between "economists' fantasies and political and industrial realities" is that not enough attention and effort have been devoted to this very important aspect of R\&D and innovation policies, since economists have excluded it from their ideal world in which the market (or its "failures") must be the sole mechanism of resource allocation. This is not to say that nothing has been done. There were a few grand exceptions in the case of scholars like Dick Nelson or Dave Mowery. But it is fair to say that this topic has been largely neglected by the profession.

But we are now entering the era of crises and Grand Challenges - climate change, food, water, and health. These Grand Challenges make a good case for revising our agenda. Increasing the rate of innovation is not enough; we do not necessarily want to increase the rate randomly in the system but in certain domains and sectors such as climate change or health-such areas where the centrality of $\mathrm{R} \& \mathrm{D}$ is emerging as a solution to structural prob- 
lems. There may be a stronger case today than in the past for targeting innovation policy in particular directions.

And because of our biased research agenda, many issues regarding the design and organization of policies aimed at responding to a Grand Challenge remain largely unexplored. While on the one hand there are now many calls for government to marshal our capabilities in science and technology to deal with problems like AIDS and global warming, on the other hand only scattered research exists on how mission-oriented government R\&D programs have in fact worked out. Our research deficit on this topic means that many issues are still poorly understood and that we are now thus perhaps unlikely to be very effective in helping to construct effective and efficient technology policies designed to respond to these Grand Challenges.

So we have the three problems, the first one known as Stigler's myth, the second concerning the inherent limitations of the exercise of translating scientific findings into the construction of a concrete innovation policy, and the third related to our own bias in the research agenda. These are obstacles but also challenges for translating innovation economics and innovation policy research into useful and applicable policy prescriptions.

\section{References}

Aghion, P., P. A. David, and D. Foray. 2009. "Science, Technology and Innovation for Economic Growth: Linking Policy Research and Practice in 'STIG systems.'” Research Policy 38 (4): 681-93.

Foray, D. 2009. "Structuring a Policy Response to a Grand Challenge." In Knowledge for Growth, Prospects for Science, Technology and Innovation, 67-75. ERA, EUR 24047, Bruxelles.

Hall, B., D. Foray, and J. Mairesse. 2007. "Pitfalls in Estimating the Returns to Corporate R\&D Using Accounting Data." First European Conference, Knowledge for Growth. October.

Klette, J., and Møen, J. 1998. "From Growth Theory to Technology Policy: Coordination Problems in Theory and Practice." Discussion papers 219, Statistics, Norway.

Stigler, G. J. 1982. "Economists and Public Policy.” Regulation, May/June, 13-17. 